\section{Elution erythrozytärer Antikörper}

K. Kleesiek ${ }^{1}$, C. Götting ${ }^{2}$, J. Diekmann ${ }^{3}$, J. Dreier ${ }^{4}$ und M. Schmidt $^{5}$

${ }^{1}$ Ehemaliger Direktor des Instituts für Laboratoriums- und Transfusionsmedizin, Herz- und Diabeteszentrum NordrheinWestfalen Ruhr-Universität Bochum, Bad Oeynhausen, Deutschland

${ }^{2}$ MVZ Labor Limbach Nürnberg GmbH, Nürnberg, Deutschland

${ }^{3}$ Institut für Laboratoriums- und Transfusionsmedizin, Herzund Diabeteszentrum NRW, Bad Oeynhausen, Deutschland ${ }^{4}$ Herz- und Diabeteszentrum Nordrhein-Westfalen; Institut für Laboratoriums- und Transfusionsmedizin, Universitätsklinik der Ruhr-Universität Bochum, Bad Oeynhausen, Deutschland

${ }^{5}$ Institut für Laboratoriums- und Transfusionsmedizin, Universitätsklinik der Ruhr-Universität Bochum, Bad Oeynhausen, Deutschland

Synonym(e) Chloroquinelution; Säureelution; Ätherelution; Wärmeelution

Englischer Begriff elution of antibodies from sensitized red cells

Definition Die Elution erythrozytärer Antikörper ist die schonende Absprengung eines Antikörpers von seinem korrespondierenden Antigen.

Die native Anlagerung von Antikörpern an Erythrozytenantigene kann die Untersuchungsergebnisse in der immunhämatologischen Diagnostik durch eine Störung der in der Regel benutzten Agglutinations- und Präzipitationstechniken verfälschen. Insofern ist vorher eine Loslösung der interferierenden Antikörpern aus ihrer Bindung an das Antigen mit Elutionstechniken erforderlich, um analytisch richtige Ergeb- nisse bei der Bestimmung sowohl von Blutgruppenmerkmalen (Blutgruppenantigenen) als auch Blutgruppenantikörpern zu erhalten. Verschiedene Elutionsverfahren stehen für dieses Ziel zur Verfügung (Ätherelution, Wärmeelution, Säureelution, Chloroquinelution).

Zwei unterschiedlichen diagnostischen Strategien lassen sich unterscheiden:

1. Elution des Antikörpers von den Erythrozyten zum Nachweis der Spezifität des angelagerten Antikörpers ( $>$ Antikörperdifferenzierung). Diese Elutionstechnik ist so angelegt, dass der Antikörper (Autoantikörper), der von den Erythrozyten entfernt (eluiert) wird, intakt erhalten bleiben soll. Der intakte Antikörper (Autoantikörper) kann anschließend mit den weiteren Verfahren der immunhämatologischen Diagnostik (Antihumanglobulintest, > Enzymtest) untersucht und spezifiziert werden.

2. Elution des Antikörpers zum Nachweis der Blutgruppenantigene der Erythrozyten. Auch bei dieser Elutionstechnik müssen die Blutgruppenmerkmale (Blutgruppenantigene) und Erythrozyten intakt bleiben, sodass die Blutgruppenantigene in der weitergehenden immunhämatologischen Diagnostik (Antihumanglobulintest) untersucht und spezifiziert werden oder auch die antikörperfreien Erythrozyten für eine Autoadsorption nicht gebundener Autoantikörper im Serum/Plasma eingesetzt werden können.

\section{Literatur}

American Association of Blood Banks, (2014) Technical manual, 18. Aufl

Salama A (2010) In: Kiefel (Hrsg) Transfusionsmedizin: Grundlagen - Therapie - Methodik, 4. Aufl. Springer, Heidelberg/Berlin/ New York, S 79-88 